${ }^{1}$ Department of Restorative Dentisty, School of Dentistry, Pontifical Catholic University of Rio Grande do Sul, Porto Alegre, Rio Grande do Sul, Brazil.
Corresponding author:

Deise Caren Somacal

School of Dentistry - Pontifical

Catholic University of Rio Grande do Sul

Avenida Ipiranga, 6681

90616-900 Porto Alegre, RS, Brazil. Phone/fax.: +55-51-3320.3538

E-mail address: deisecaren@gmail.com (iD) https://orcid.org/0000-0003-0861-3189

Received: April 30, 2019

Accepted: September 142019

\section{Surface roughness of monolithic zirconia ceramic submitted to different polishing systems}

\author{
Deise Caren Somacal ${ }^{1, *}$, Júlia Willers Dreyer ${ }^{1}$, Patrícia \\ Danesi ${ }^{1}$, Ana Maria Spohr ${ }^{1}$
}

Aim: The objective was to evaluate, quantitative and qualitative, the abrasive effect of three polishing systems on the monolithic zirconia ceramic. Methods: Thirty disk-shaped samples of Yttria Tetragonal Zirconia Polycrystal (Y-TZP) were randomly distributed in three groups $(n=10)$ according to polishing system: G1- Komet system (KO); G2 - CeraGloss system (CG); G3 - Eve Diacera system (EV). The surface roughness ( $\mathrm{Ra}$ ) was obtained with Rugosimeter in four different moments: a) initial - glaze sample (Ra0); b) after occlusal adjustment with diamond burs (Ra1); c) after polishing with the abrasive systems (Ra2); d) after polishing with felt disc and diamond paste (Ra3). Four additional samples were observed in scanning electron microscopy (SEM). Results: According to the Generalized Estimating Equation followed by the Bonferroni test $(a=0.05)$, the CG provided the lowest $\mathrm{Ra} 2(0.63 \mu \mathrm{m})$, not differing significantly from the $\mathrm{KO}(0.78 \mu \mathrm{m})$. The highest Ra2 was obtained with the EV $(0.97 \mu \mathrm{m})$, which did not differ significantly from the KO. There was no statistical difference in Ra between the polishing with the abrasive systems (Ra2) and the final polishing with diamond paste (Ra3). SEM images showed that the polishing systems did not completely remove the grooves caused by the diamond burs during the occlusal adjustment. Conclusion: It was concluded that CG promoted smoother surface of the monolithic zirconia ceramic compared to EV, and intermediate smoothness was obtained with $\mathrm{KO}$.

Keywords: Dental polishing. Surface properties. Ceramics. 


\section{Introduction}

There are different types of dental ceramics for tooth restoration nowadays. The choice of the material depends on some factors, such as aesthetics and the fracture strength. Metal-free ceramic restorations have become popular among patients and dentists. These restorations can be obtained through laboratory-based methods which have been described as time-consuming, sensitive in technique and unpredictable due to many variables ${ }^{1}$. Another alternative for dentists and laboratories is the computer-aided design/computer-aided manufacturing (CAD-CAM) technology. CAD-CAM system presents greater precision from industrially manufactured blocks, besides the optimization of time and reduction of clinical appointments ${ }^{2}$.

Advances in the technique of making metal-free ceramic restorations have allowed the creation of monolithic restorations. They can be obtained in a single moment by the CADCAM method, reducing manufacturing time, and using only one type of ceramic. Within a wide range of monolithic materials available for CAD-CAM, monolithic high translucent Ytria Tetragonal Zirconia Polycrystals (Y-TZP) stands out due to its favorable mechanical and aesthetic properties. This material has characteristics of color stability, hardness, wear resistance and translucency. In addition, it has low thermal conductivity, high flexural strength and phase transformation capacity, preventing the propagation of cracks in areas of greater occlusal stress ${ }^{3-5}$. The technique of obtaining this monolithic restoration is simpler than porcelain-veneered Y-TZP crown cores, favoring the strength of the restoration'.

Despite the high precision of the restorations made by the CAD-CAM system, adjustments are often necessary, before or after luting. Finishing or even polishing the surface of the Y-TZP after sintering can create a layer of compressive stress due to the occurrence of phase reversal. The Y-TZP in the tetragonal phase converts to the monoclinic phase $(\mathrm{t} / \mathrm{m})$ causing a decrease in its mechanical properties ${ }^{7}$. Therefore, this adjustment requires precaution so that there is no change in the Y-TZP structure or excessive roughness of the restoration which can compromising its longevity ${ }^{8,9}$.

In case of restoration adjustment after cementation, the only possibility of restoring the surface smoothness again is through the mechanical polishing procedure. Polishing is a process characterized by the production of smoothness and surface gloss by the use of abrasive instruments. The objective of these procedures is to eliminate the roughness caused by the diamond burs, in order to increase patient comfort, decrease bacterial plaque accumulation and avoid excessive wear of the antagonist tooth ${ }^{10,11}$. There are several ceramic finishing and polishing systems on the market, and it is important to verify the ability of these instruments to polish the ceramic.

The aim of this study was to evaluate quantitatively and qualitatively the surface roughness obtained with three polishing systems on the monolithic zirconia ceramic. The study followed the null hypothesis that there is no significant difference in surface roughness among the different polishing systems.

\section{MATERIAL AND METHODS}

The materials used in this study are described in Table 1. 
Table 1. Materials used in this study.

\begin{tabular}{lc}
\hline Material & Fabricante \\
\hline Komet System ZR & Komet, São Paulo, Brazil. \\
\hline CeraGloss System & Edenta AG, Aubonne, Switzerland. \\
\hline Eve Diacera System & EVE Ernst Vetter GmbH, Keltern, Germany. \\
\hline Diamond Burs (4138, 4138F, 4138FF) & KG Sorensen, São Paulo, Brazil. \\
\hline Felt discs (Diamond Flex) & FGM, Santa Catarina, Brazil. \\
\hline Diamond paste (Diamond Excel) & FGM, Santa Catarina, Brazil. \\
\hline Ceramic disks (Zircônia Lava Frame) & 3M ESPE, St. Paul, United State of America. \\
\hline
\end{tabular}

\section{Obtaining the ceramic disks}

Thirty disk-shaped samples of Y-TZP with $7 \mathrm{~mm}$ diameter and $3 \mathrm{~mm}$ height were obtained. The samples were made by a prosthetic laboratory that has the computerized system. In this system, a pre-sintered zirconia blocks were milled into the desired sample shape and sintered according to the manufacturer's recommendations. Subsequently, the surface was finished with \# 400, \# 600 and \# 1200 with silicon carbide paper with running water in a polishing machine (Panambra, São Paulo, SP, Brazil) for surface standardization. The samples were also ultrasonically cleaned (Odontobrás, Ribeirão Preto, SP, Brazil) in distilled water for 10 min to ensure a contaminant-free ceramic surface, followed by drying and glaze in prosthetic laboratory.

\section{Surface preparation of sample}

The 30 Y-TZP samples were randomly divided into three groups $(n=10)$ according to the polishing system used: Group 1-Komet System (KO); Group 2 - CeraGloss System (CG) and Group 3 - Eve Diacera System (EV). The diamond bur 4138, in high speed handpiece with refrigeration, was applied for $3 \mathrm{~s}$ on the $\mathrm{Y}$-TZP surface to simulate the occlusal wear. This procedure was followed by the 4138F and 4138FF diamond burs, which were changed every five samples. After the wear process, the ceramic surface was polished with one of the polishing systems that consisted of different tips. Each tip was applied in low speed for $30 \mathrm{~s}$ according to the following sequence:

A. KO system - first step: blue abrasive called a pre-polisher; second step: gray abrasive for final polish.

B. CG system - first step: green abrasive used for finishing and rapid wear of the material; second step: blue abrasive to smooth the surface; third step: yellow abrasive for final polish.

C. EV system - first step: green abrasive used for finishing; second step: pink abrasive for final polish.

In order to complete the polishing, a felt disc was used with a diamond polishing paste for $30 \mathrm{~s}$. After polishing, the specimens were ultrasonically cleaned in distilled water for $10 \mathrm{~min}$. All procedures were done by the same operator. 


\section{Quantitative analysis of surface roughness}

The surface roughness of all ceramic samples was measured with a rugosimeter (Model SJ-210, Mitutoyo, Kanagawa, Japan) at four different moments: glaze sample (Ra0), after occlusal adjustment with diamond burs (Ra1), after polishing with the polishing systems (Ra2), after polishing with felt disc and diamond paste (Ra3). Three consecutive measurements were performed in three different regions of the sample (one central, one to the right and one to the left), with a cut-off of 0.25 , and the average of the three measurements was obtained.

\section{Qualitative analysis of surface roughness}

Four additional samples were obtained, one sample being glazed and the other representing each of the polishing systems. The samples were ultrasonically cleaned with distilled water for 15 min, dried in a dehumidifier with silica gel for three days and sputter-coated. Then, the surface topography of these samples was observed by scanning electron microscopy (SEM) (Phillips XL 30, Philips Electronic Instruments Inc., Mahwah, NJ, EUA) at 500× magnification.

\section{Statistical analysis}

The surface roughness values were submitted to the Shapiro-Wilk normality test. After the values were analysed by the Generalized Estimating Equation followed by the Bonferroni test. The significance level was $5 \%$.

\section{RESULTS}

\section{Quantitative Analysis}

There was no significant difference in surface roughness among the samples at $\mathrm{RaO}$ (glazed samples). The diamond burs (Ra1) increased significantly the surface roughness of all samples when compared with Ra0. CG system provided the lowest $\operatorname{Ra2}(0.63 \mu \mathrm{m})$, not differing significantly from $\mathrm{KO}$ system $(0.78 \mu \mathrm{m})$. The highest $\mathrm{Ra} 2$ was obtained with EV system $(0.97 \mu \mathrm{m})$, which did not differ significantly from $\mathrm{KO}$ system. The polishing with the diamond paste (Ra3) reduced the surface roughness, but there was no significant difference in relation to the polishing systems (Ra2) (Table 2).

Table 2. Surface roughness values $(\mu \mathrm{m})$ and standard-deviations of the different groups.

\begin{tabular}{lccc}
\hline Surface treatment & $\begin{array}{c}\text { Komet System } \\
\text { (KO) }\end{array}$ & $\begin{array}{c}\text { CeraGloss System } \\
(\text { CG })\end{array}$ & $\begin{array}{c}\text { Eve Diacera System } \\
\text { (EV) }\end{array}$ \\
\hline Initial - Glazed Sample (Ra0) & $0.61^{\mathrm{Ab}}( \pm 0.24)$ & $0.48^{\mathrm{Ab}}( \pm 0.16)$ & $0.41^{\mathrm{Ac}}( \pm 0.25)$ \\
\hline After abrasion with diamond burs (Ra1) & $1.03^{\mathrm{Aa}}( \pm 0.44)$ & $0.96^{\mathrm{Aa}}( \pm 0.34)$ & $1.22^{\mathrm{Aa}}( \pm 0.48)$ \\
\hline After polishing systems (Ra2) & $0.78^{\mathrm{ABab}}( \pm 0.31)$ & $0.63^{\mathrm{Bb}}( \pm 0.24)$ & $0.97^{\mathrm{Aab}}( \pm 0.34)$ \\
\hline After felt disc with diamond paste $(\mathrm{Ra} 3)$ & $0.72^{\mathrm{ABb}}( \pm 0.16)$ & $0.56^{\mathrm{Bb}}( \pm 0.21)$ & $0.87^{\mathrm{Ab}}( \pm 0.28)$ \\
\hline
\end{tabular}

Means followed by the same capital letter in the lines and the same lowercase letter in the columns do not differ statistically from each other by the Bonferroni test. Significance level a=0,05. 


\section{Qualitative Analysis}

Figure 1 shows the surface topography of Y-TZP after the different treatments. It is observed that the polishing systems did not completely remove the grooves caused by the diamond burs during the occlusal adjustment (Figures 1B, 1C and 1D). It also did not reproduce the smooth surface of the glazed Y-TZP (Figure 1A). More grooves remained on the surface after polishing with EV system (Figure 1D).

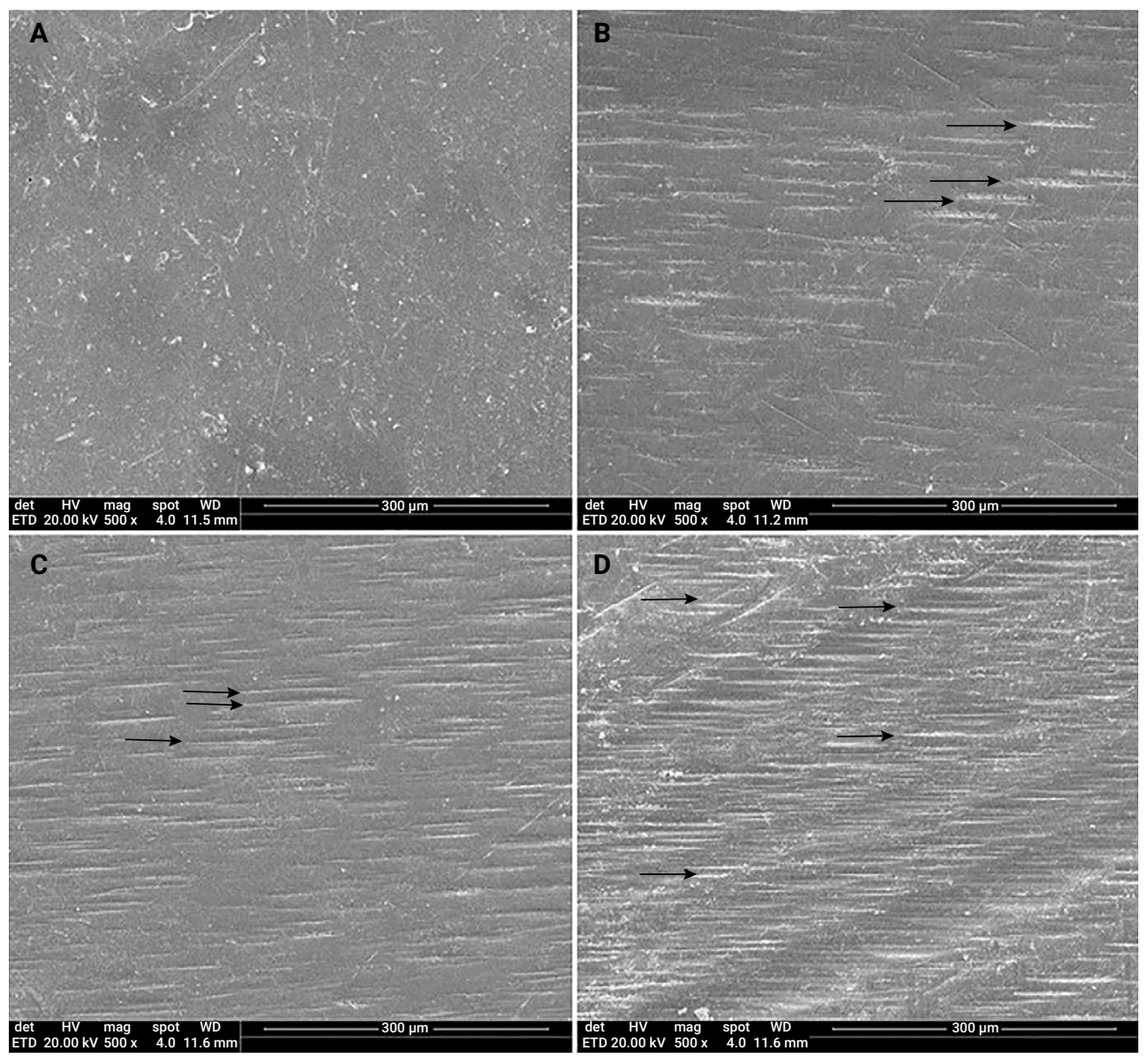

Figure 1. SEM images of Y-TZP surface (500x). (A): glazed surface; (B): polished with CeraGloss System; (C): polished with Komet System; (D): polished with Eve Diacera System. Black arrows indicate grooves caused by the diamond burs.

\section{DISCUSSION}

According to the results, the surface roughness of monolithic zirconia was influenced by polishing systems. Therefore, the null hypothesis was rejected.

The dental market offers different polishing systems. Each polishing system is composed of a primary abrasive, which determines the polishing effect, as well as 
a complementary abrasive and a binder material to hold these abrasive particles and shape the instrument ${ }^{12}$. Mohs scale quantifies the hardness of the minerals in values from 1 to 10. Y-TZP has an absolute hardness value of 9, requiring an abrasive material composed of diamond, silicon carbide, aluminum oxide or zirconium oxide $^{12}$. Goo et al. ${ }^{13}$ stated that diamond-impregnated polishing systems were more effective than silica carbide-impregnated ones in reducing the surface roughness of Y-TZP. According to the manufacturers' catalogs, the three polishing systems used in the present study are impregnated with diamond particles and are suitable for $\mathrm{Y}$-TZP restorations.

CG system showed the lowest surface roughness on Y-TZP, not differing from KO system. These results corroborate with another study ${ }^{14}$. Al-Haj Husain et al. ${ }^{5}$ reported that the effectiveness of CG system is related to minor loss of abrasive particles during the polishing on Y-TZP surface. The authors stated that roughness of the polishing instrument and the integrity of its surface are important for polishing effectiveness.

EV system promoted higher surface roughness without significant difference from KO system. Not all diamond-impregnated polishing systems work alike on the Y-TZP, since the effectiveness of the polishing systems is related to the percentage of diamond abrasive particles and the percentage of binder ${ }^{13}$. In general, none of the polishing systems tested in the present study created a smoother surface than the glazed Y-TZP, which corroborates with another study ${ }^{15}$.

The increase of surface roughness on dental ceramics after occlusal adjustment causes wear on the surface of antagonist teeth, especially in sound teeth ${ }^{16,17}$. Dental ceramics present greater hardness than dental surface, causing cracks on dental enamel and loss of its surface structure ${ }^{13}$. However, Y-TZP hardness is double than other dental ceramics ${ }^{18}$, tending a greater wear of the antagonist tooth and detrimental effects. In the present study, the specimens were glazed before the simulation of occlusal wear and Y-TZP surface may also be polished instead of glazed. According to Janyavula et al. ${ }^{19}$ polished $Y$-TZP is wear-friendly to the opposing tooth and glazed Y-TZP causes more wear of antagonist tooth. Therefore, the glazing of Y-TZP should be avoided unless there is a high esthetic demand in which it should be polished and then glazed $^{19}$.

A systematic review analyzed the abrasion effect on the mechanical behavior of Y-TZP. It concluded that necessary adjustments are possible on ceramic surface without causing damage to the Y-TZP strength. To avoid jeopardizing the Y-TZP restoration, a protocol which introduces the least possible surface defects should be chosen. Thus, it is suggested using a rotating instrument at low speed, allowing movement control, besides instruments with abrasive particles up to $50 \mu \mathrm{m}^{20}$. These requirements were followed in the present study.

It was also evaluated the polishing with a diamond paste as the final step in the sequence. This procedure is indicated to increase the smoothness of ceramic surfaces ${ }^{15}$. Based on the results, surface roughness was reduced after diamond paste polishing, but there was no significant difference when compared to polishing systems. These results showed that the diamond paste had little effect in obtaining a smoother surface on Y-TZP surface. 
The surface roughness also influences biofilm formation; when higher than $0.2 \mu \mathrm{m}$ it favours bacterial adhesion in restorative materials ${ }^{21,22}$. The surface roughness values were 3 to 5 times higher than $0.2 \mu \mathrm{m}$ after the use of polishing systems in the present study. Happe et al. ${ }^{23}$ obtained surface roughness of $0.17 \mu \mathrm{m}$ for KO system on Y-TZP surface. However, no diamond bur was used prior to the polishing system, which could justify the difference in surface roughness values between the studies.

The SEM images showed that the three polishing systems were not able to completely remove the grooves created by the diamond burs. The smooth surface observed on the glazed Y-TZP was not reproduced by the polishing systems, which corroborates with another study ${ }^{24}$. EV system obtained the highest surface roughness value and more grooves were observed on the Y-TZP surface. Therefore, the quantitative analysis of the surface roughness agreed with the qualitative analysis of the ceramic surface by SEM.

Although there are different results in the literature, most of the studies evaluating polishing procedures is unanimous in pointing out the advantages of a smooth surface. This is also important for the aesthetic viewpoint as well as for patient's comfort. Jones et al. ${ }^{25}$ determined a threshold of detection values for surface roughness of restorations by patients using their tongue. It was observed that the volunteers were able to distinguish between roughness values of $0.5 \mu \mathrm{m}$ or less with their tongue. So, it is expected that patients may detect differences on surface roughness between the diamond burs and the polishing systems. Probably, patients would not detect differences on surface roughness among the polishing systems. In addition, the authors of a clinical study claimed that polished $\mathrm{Y}$-TZP is a versatile restorative material for its aesthetic properties and high strength, being promissory ${ }^{26}$.

The limitation of the present study is the polishing procedures performed on flat surfaces samples. These flat surfaces differ from the clinical reality, as the occlusal surfaces of molars and premolars have anatomical features that could make the polishing procedure harder.

The following conclusions can be drawn:

- The polishing systems used in this study were able to reduce the roughness of the monolithic zirconia ceramic caused by the diamond burs. However, they did not remove the grooves, presenting greater roughness when compared to the glazed surface.

- CeraGloss system promoted smoother surface of the monolithic zirconia ceramic compared to Eve Diacera system, and intermediate smoothness was obtained with Komet system.

- The polishing with diamond paste did not significantly reduce the surface roughness.

\section{ACKNOWLEDGEMENTS}

This study was financed in part by the Coordenação de Aperfeiçoamento de Pessoal de Nível Superior - Brasil (CAPES) - Finance Code 001. 


\section{CONFLICTS OF INTEREST}

\section{The author does not have any financial interest in the companies whose materials are included in this article.}

\section{REFERENCES}

1. Senyilmaz DP, Canay S, Heydecke G, Strub JR. Influence of thermomechanical fatigue loading on the fracture resistance of all-ceramic posterior crowns. Eur J Prosthodont Restor Dent. 2010;18(2):50-4.

2. Li RW, Chow TW, Matinlinna JP. Ceramic dental biomaterials and CAD/CAM technology: state of the art. J Prosthodont Res. 2014 Oct;58(4):208-16. doi: 10.1016/j.jpor.2014.07.003.

3. Kim HK, Kim SH, Lee JB, Ha SR. Effects of surface treatments on the translucency, opalescence, and surface texture of dental monolithic zirconia ceramics. J Prosthet Dent. 2016 Jun;115(6):773-9. doi: 10.1016/j.prosdent.2015.11.020.

4. Gui J, Xie Z. Phase transformation and slow crack growth study of Y-TZP dental ceramic. Mater Sci Eng A. 2016 Sep;676:531-5. doi: 10.1016/j.msea.2016.09.026.

5. Al-Haj Husain N, Camilleri J, Özcan M. Effect of polishing instruments and polishing regimens on surface topography and phase transformation of monolithic zirconia: an evaluation with XPS and XRD analysis. J Mech Behav Biomed Mater. 2016 Dec;64:104-12. doi: 10.1016/j.jmbbm.2016.07.025.

6. Johansson C, Kmet G, Rivera J, Larsson C, Vult Von Steyern P. Fracture strength of monolithic all-ceramic crowns made of high translucent yttrium oxide-stabilized zirconium dioxide compared to porcelain-veneered crowns and lithium disilicate crowns. Acta Odontol Scand. 2014 Feb;72(2):145-53. doi: 10.3109/00016357.2013.822098.

7. Aboushelib MN, Feilzer AJ, Kleverlaan CJ. Bridging the gap between clinical failure and laboratory fracture strength tests using a fractographic approach. Dent Mater. 2009 Mar;25(3):383-91. doi: 10.1016/j.dental.2008.09.001.

8. Egilmez F, Ergun G, Cekic-Nagas I, Vallittu PK, Lassila LVJ. Factors affecting the mechanical behavior of Y- TZP. J Mech Behav Biomed Mater. 2014 Sep;37:78-87. doi: 10.1016/j.jmbbm.2014.05.013.

9. Song JY, Park SW, Lee K, Yun KD, Lim HP. Fracture strength and microstructure of Y- TZP zirconia after different surface treatments. J Prosthet Dent. 2013 Oct;110(4):274-80. doi: 10.1016/S0022-3913(13)60376-5.

10. Hmaidouch R, Müller WD, Lauer HC, Weigl P. Surface roughness of zirconia for full-contour crowns after clinically simulated grinding and polishing. Int J Oral Sci. 2014 Dec;6(4):241-6. doi: 10.1038/ijos.2014.34.

11. Rashid $\mathrm{H}$. The effect of surface roughness on ceramics used in dentistry: A review of literature. Eur $\mathrm{J}$ Dent. 2014 Oct;8(4):571-9. doi: 10.4103/1305-7456.143646.

12. Koudi MS. Dental Materials: Prep manual for undergraduates. New Delhi: Harcourti-India-Private; 2007.

13. Goo CL, Yap A, Tan K, Fawzy AS. Effect of Polishing Systems on Surface Roughness and Topography of Monolithic Zirconia. Oper Dent. 2016 Jul-Aug;41(4):417-23. doi: 10.2341/15-064-L.

14. Park C, Vang MS, Park SW, Lim HP. Effect of various polishing systems on the surface roughness and phase transformation of zirconia and the durability of the polishing systems. J Prosthet Dent. 2017 Mar;117(3):430-7. doi: 10.1016/j.prosdent.2016.10.005.

15. Steiner R, Beier US, Heiss-Kisielewsky I, Engelmeier R, Dumfahrt H, Dhima M. Adjusting dental ceramics: An in vitro evaluation of the ability of various ceramic polishing kits to mimic glazed dental ceramic surface. J Prosthet Dent. 2015 Jun;113(6):616-22. doi: 10.1016/j.prosdent.2014.12.007. 
16. Delong R, Douglas WH, Sakaguchi RL, Pintado MR. The wear of dental porcelain in an artificial mouth. Dent Mater. 1986 Oct;2(5):214-9.

17. Jagger DC, Harrison A. An in vitro investigation into the wear effects of unglazed, glazed, and polished porcelain on human enamel. J Prosthet Dent. 1994 Sep;72(3):320-3.

18. Raigrodski AJ. Contemporary materials and technologies for all- ceramic fixed partial dentures: A review of the literature. J Prosthet Dent. 2004 Dec;92(6):557-62.

19. Janyavula S, Lawson N, Cakir D, Beck P, Ramp LC, Burgess JO. The wear of polished and glazed zirconia against enamel. J Prosthet Dent. 2016 Aug 1. pii: S0022-3913(16)30197-4. doi: 10.1016/j.prosdent.2016.04.026.

20. Pereira GKR, Fraga S, Montagner AF, Soares FZM, Kleverlaan CJ, Valandro LF. The effect of grinding on the mechanical behavior of Y-TZP ceramics: A systematic review and meta-analyses. J Mech Behav Biomed Mater. 2016 Oct;63:417-442. doi: 10.1016/j.jmbbm.2016.06.028.

21. Bollen CM, Lambrechts P, Quirynen M. Comparison of surface roughness of oral hard materials to the threshold surface roughness for bacterial plaque retention: a review of the literature. Dent Mater. 1997 Jul;13(4):258-69.

22. Teughels W, Van Assche N, Sliepen I, Quirynen M. Effect of material characteristics and/or surface topography on biofilm development. Clin Oral Implants Res. 2006 Oct;17 Suppl 2:68-81.

23. Happe A, Röling N, Schäfer A, Rothamel D. Effects of different polishing protocols on the surface roughness of Y-TZP surfaces used for custom-made implant abutments: a controlled morphologic SEM and profilometric pilot study. J Prosthet Dent. 2015 May;113(5):440-7. doi: 10.1016/j. prosdent.2014.12.005.

24. Mohammadi-Bassir M, Babasafari M, Rezvani MB, Jamshidian M. Effect of coarse grinding, overglazing, and 2 polishing systems on the flexural strength, surface roughness, and phase transformation of yttrium-stabilized tetragonal zirconia. J Prosthet Dent. 2017 Nov;118(5):658-665. doi: 10.1016/j.prosdent.2016.12.019.

25. Jones CS, Billington RW, Pearson GJ. The in vivo perception of roughness of restorations. Br Dent J. 2004 Jan 10;196(1):42-5.

26. Esquivel-Upshaw JF, Kim MJ, Hsu SM, Abdulhameed N, Jenkins R, Neal D, et al. Randomized clinical study of wear of ebamel antagonists against polished monolithic zirconia crowns. J Dent. 2018 Jan;68:19-27. doi: 10.1016/j.jdent.2017.10.005. 